\title{
Impact of COVID-19 on eating habits, physical activity and sleep in Brazilian healthcare professionals
}

\author{
Impacto da COVID-19 nos hábitos alimentares, atividade física e sono em profissionais de \\ saúde brasileiros
}

Isabella Araújo MOTA', Gilberto Diniz de OLIVEIRA SOBRINHO², Luara Paiva Silva MORAIS³, Thamires Ferreira DANTAS ${ }^{4}$

\begin{abstract}
Background: During the coronavirus disease 2019 (COVID-19) pandemic, Brazilian healthcare professionals could have been experiencing impacts on their routine, behavior and mental health. Objective: To investigate changes in the daily life and sleeping habits of healthcare professionals in Brazil. Methods: We conducted an observational and cross-sectional study from May to July 2020. A Google Forms questionnaire was made available to Brazilian healthcare professionals on the WhatsApp mobile application and through the website of the Brazilian Hospital Services Company. Results: The sample $(n=710)$ was mostly composed of women $(80.8 \%)$, aged between 30 and 40 years old (46.6\%), predominantly physicians (41.8\%) and residing mostly in the state of Paraíba (66.9\%), Brazil. Approximately two-thirds of the total sample had some sleep-related complaints, $25.8 \%$ due to difficulty initiating sleep, $29.6 \%$ due to difficulty staying asleep and $32.5 \%$ due to early morning waking. From the population studied, $28.7 \%(n=204)$ reported the use of insomnia medication, and $60.3 \%(n=123)$ of these were self-medicating. Some participants reported a change in diet ( $n=557 ; 78.5 \%)$, especially related to the increase in carbohydrate intake $(n=174 ; 24.5 \%)$, and $27 \%$ ( $n=192)$ of the individuals reported an increase of the consumption of alcoholic beverages. Of the total, 561 (81.8\%) reported a change in the practice of physical activity. Conclusion: In this study, Brazilian healthcare professionals showed aspects of quality of life that were more affected during the COVID-19 pandemic than the prevalence seen in surveys of international studies for the general population.
\end{abstract}

Keywords: Coronavirus; Eating Habits; Physical Activity; Mental Health; Healthcare Professionals.

\section{RESUMO}

Antecedentes: Durante a pandemia de COVID-19, os profissionais de saúde brasileiros podem estar sofrendo impactos em sua rotina, comportamento e saúde mental. Objetivo: Investigar mudanças na vida diária e nos hábitos de sono de profissionais de saúde no Brasil. Métodos: Estudo observacional e transversal, que ocorreu de maio a julho de 2020. Um questionário da Google (Google forms) foi disponibilizado aos profissionais de saúde brasileiros no aplicativo móvel WhatsApp e no site da Empresa Brasileira de Serviços Hospitalares. Resultados: A amostra $(n=710)$ foi composta em sua maioria por mulheres $(80,8 \%)$, com idade entre 30 e 40 anos $(46,6 \%)$, predominantemente composta de médicos $(41,8 \%)$ e residentes, em sua maioria no estado da Paraíba (66,9\%). Aproximadamente dois terços do total da amostra tinham algumas queixas relacionadas ao sono: 25,8\% sobre a dificuldade de iniciar o sono, 29,6\% sobre a dificuldade de mantê-lo e 32,5\% sobre despertar precoce pela manhã. Da amostra, 28,7\% ( $n=204)$ referiram fazer uso de medicamentos para insônia e 60,3\% ( $n=123)$ desses realizaram automedicação. Alguns participantes relataram mudança na dieta alimentar ( $n=557$; $78,5 \%$ ), principalmente relacionada ao aumento da ingestão de carboidratos ( $n=174 ; 24,5 \%$ ). Observou-se também que $27 \%$ ( $n=192)$ dos indivíduos relataram aumento no consumo de bebidas alcoólicas. Do total, 561 (81,8\%) relataram mudança na prática de atividade física. Conclusão: Nesta pesquisa, os profissionais de saúde brasileiros apresentaram aspectos da qualidade de vida que foram mais afetados durante a pandemia de COVID-19 do que as prevalências obtidas em pesquisas de estudos internacionais para a população em geral.

Palavras-chave: Novo Coronavírus; Comportamento Alimentar; Atividade Física; Saúde Mental; Profissionais de Saúde.

\footnotetext{
'Universidade Federal da Paraíba, João Pessoa PB, Brazil.

${ }^{2}$ Centro de Atenção Psicossocial de João Pessoa, João Pessoa PB, Brazil.

${ }^{3}$ Hospital de Emergência e Trauma Senador Humberto Lucena, João Pessoa PB, Brazil.

${ }^{4}$ Singular Clínica, João Pessoa PB, Brazil.

Isabella Araújo MOTA (ID https://orcid.org/0000-0003-1147-7894; Gilberto Diniz de OLIVEIRA SOBRINHO (ID) https://orcid.org/0000-0002-3180-8120; Iuara Paiva Silva MORAIS (D) https://orcid.org/0000-0002-6181-3879; Thamires Ferreira DANTAS (D) https://orcid.org/0000-0001-6941-2693

Correspondence: Isabella Araújo Mota; E-mail: isabella_mota@yahoo.com.br.

Conflict of interest: There is no conflict of interest to declare.

Authors' contributions: IAM: conceptualization, investigation, methodology, project administration, visualization, writing-original draft, writing-review \& editing. GDOS: formal analysis, visualization, writing-original draft, writing-review \& editing. TFD: conceptualization, methodology, supervision. IPSM: conceptualization, formal analysis, writing-review \& editing.

Received on October 19, 2020; Received in its final form on February 10, 2021; Accepted on February 16, 2021.
} 


\section{INTRODUCTION}

The pneumonia caused by SARS-CoV-2 was first described in Wuhan, a city in southern China ${ }^{1}$, spread nationally and internationally and led to the declaration of pandemic status by the World Health Organization on March 11, 2020, after the registration of more than 118 thousand cases of COVID-19 and 4,292 deaths worldwide 2 . In Brazil, on August 9th, 2020, a level of 100 thousand deaths attributed to COVID-19 was reached, with approximately 1,000 deaths per day since May 19, $2020^{3}$.

The social isolation used worldwide as an effective prevention from the contagion of COVID-19 has shown several side effects related to mental health ${ }^{4}$, which led to a lack of control of other clinical comorbidities and negative impacts on social, intellectual, cultural, labor and financial aspects ${ }^{5}$. A study carried out in China found that healthcare professionals who were at the fighting forefront of COVID-19 were at high risk of depression, anxiety, insomnia and post-traumatic stress symptoms ${ }^{6}$.

Thus, this study aimed to investigate changes in daily life habits related to sleep, eating and physical activity of healthcare professionals in Brazil to understand the impact of the COVID-19 pandemic on these people's daily lives. We hypothesized that all healthcare professionals experienced a negative impact on quality of life during the pandemic when evaluating together diet, physical activity, alcohol consumption and sleep. A secondary hypothesis is that physicians would report worse results in sleep habits.

\section{METHODOLOGY}

This was an observational and cross-sectional study that was conducted during the peak of the COVID-19 pandemic in Brazil, from May to July 2020. The research was approved by the ethics committee of the Federal University of Paraiba and by the National Commission for Ethics and Research through Approval No. 4,157,408. A Google Forms questionnaire was made available to healthcare professionals from all Brazil through online groups of healthcare professionals on the WhatsApp mobile application and through the website of the Brazilian Hospital Services Company, responsible for managing 41 federal university hospitals ${ }^{7}$. The access to the forms was conditioned to the agreement of the Free and Informed Consent Term, which dealt with anonymity, confidentiality of information, non-mandatory participation in the research and the possibility of quitting the study at any time.

The inclusion criteria were being a health professional and working during the COVID-19 pandemic. There was no exclusion criterion in this study. The electronic form used did not allow filling it out in an incorrect or incomplete way. This study did not receive any specific grant from funding agencies in the public, commercial, or non-profit sectors.
Healthcare professionals answered the Insomnia Severity Index (ISI-7), a questionnaire validated for Brazilian Portuguese $^{8}$ and also validated as an online application tool, in addition to questions about characterization of physical activity and nutritional profile.

\section{Data analysis}

The data were tabulated in a digital spreadsheet and analyzed statistically. Descriptive analysis was performed using measures of absolute frequency, relative frequency, measure of central tendency, mean and standard deviation. Inferential analysis was also performed using the hypothesis test for proportions to obtain the proportion of the frequency of responses to the questionnaire items. The statistical software $R$, version 3.6.2, was used, and the p-value was determined using Pearson's chi-square test, considering a statistical significance level of $5 \%(p<0.05)$.

\section{RESULTS}

Table 1 contains data referring to the characterization of the 710 respondents, mostly women $(n=574 ; 80.8 \%)$, between 30 and 40 years of age $(n=331 ; 46.6 \%)$. The survey included healthcare professionals from several backgrounds, mainly physicians $(\mathrm{n}=297 ; 41.8 \%)$, nurses $(\mathrm{n}=96 ; 13.5 \%)$, physical therapists $(\mathrm{n}=79 ; 11.1 \%)$ and nursing technicians $(\mathrm{n}=73$; $10.3 \%$ ). These professionals were distributed in the federal district and in more than 21 of the 26 Brazilian states and the majority were in the state of Paraíba $(n=475 ; 66.9 \%)$.

The length of professional experience ranged from 1 to 48 years and the work experience at the time of the research included hospital wards for the majority $(\mathrm{n}=123 ; 17.3 \%)$, followed by intensive care units ( $\mathrm{n}=97 ; 13.7 \%)$, outpatient clinics $(\mathrm{n}=92 ; 13.0 \%)$, private clinics $(\mathrm{n}=90 ; 12.7 \%)$, hospital urgency/ emergency $(n=62 ; 8.7 \%)$, emergency care units (emergency units) non-hospital emergency services in the public health system in Brazil ( $\mathrm{n}=48 ; 6.8 \%)$, family health units $(\mathrm{n}=48 ; 6.8 \%)$, surgical units ( $\mathrm{n}=36 ; 5.1 \%)$ and call centers $(\mathrm{n}=26 ; 3.7 \%)$.

Regarding sleep (ISI-7 questionnaire), most participants reported moderate difficulty in falling asleep $(n=215 ; 30.3 \%)$, slight difficulty in maintaining sleep $(\mathrm{n}=215 ; 30.3 \%)$ and no difficulty with waking up early $(\mathrm{n}=231 ; 32.5 \%)$ (Table 2). In addition, they showed dissatisfaction with the current sleeping pattern ( $\mathrm{n}=300 ; 42.3 \%$ ), with the way this pattern interferes in activities of daily life $(n=287 ; 40.4 \%)$, and they also said they were concerned about/stressed with the sleeping problem $(\mathrm{n}=248 ; 34.9 \%)$ (Table 2 ).

It was observed that other healthcare professionals had more complaints related to sleep than physicians specifically, although both groups claimed to be dissatisfied with the current sleeping pattern (Table 3), and present moderate difficulty in falling asleep and staying asleep, while most physicians stated mild difficulty or no difficulty. Proportionally, 
Table 1. Characterization of the sample of healthcare professionals surveyed during the SARS-CoV-2 pandemic.

\begin{tabular}{|c|c|c|}
\hline & $n$ & $\%$ \\
\hline \multicolumn{3}{|l|}{ Sex } \\
\hline Women & 574 & 80.8 \\
\hline Men & 136 & 19.2 \\
\hline \multicolumn{3}{|l|}{ Age range } \\
\hline $20-30$ years old & 159 & 22.4 \\
\hline $30-40$ years old & 331 & 46.6 \\
\hline 40-50 years old & 138 & 19.4 \\
\hline 50-60 years old & 59 & 8.3 \\
\hline Over 60 years old & 23 & 3.2 \\
\hline Physician & 297 & 41.8 \\
\hline Other healthcare professionals & 413 & 58.2 \\
\hline Social worker & 12 & 1.7 \\
\hline Biomedical professional & 5 & 0.7 \\
\hline Dentist & 15 & 2.1 \\
\hline Nurse & 96 & 13.5 \\
\hline Pharmacist & 13 & 1.8 \\
\hline Physiotherapist & 79 & 11.1 \\
\hline Speech therapist & 39 & 5.5 \\
\hline Nutritionist & 33 & 4.6 \\
\hline Psychologist & 21 & 3.0 \\
\hline Laboratory technician & 1 & 0.1 \\
\hline Radiology technician & 1 & 0.1 \\
\hline Nursing technician & 73 & 10.3 \\
\hline Occupational therapist & 13 & 1.8 \\
\hline \multicolumn{3}{|l|}{ State of professional activity } \\
\hline Amazonas & 4 & 0.6 \\
\hline Bahia & 4 & 0.6 \\
\hline Ceará & 8 & 1.1 \\
\hline Distrito Federal & 15 & 2.1 \\
\hline Espírito Santo & 1 & 0.1 \\
\hline Goiás & 9 & 1.3 \\
\hline Maranhão & 6 & 0.8 \\
\hline Mato Grosso & 12 & 1.7 \\
\hline Mato Grosso do Sul & 2 & 0.3 \\
\hline Minas Gerais & 10 & 1.4 \\
\hline Pará & 4 & 0.6 \\
\hline Paraíba & 475 & 66.9 \\
\hline Paraná & 25 & 3.5 \\
\hline Pernambuco & 31 & 4.4 \\
\hline Piauí & 9 & 1.3 \\
\hline Rio de Janeiro & 6 & 0.8 \\
\hline Rio Grande do Norte & 24 & 3.4 \\
\hline Rio Grande do Sul & 1 & 0.1 \\
\hline Roraima & 1 & 0.1 \\
\hline Santa Catarina & 4 & 0.6 \\
\hline São Paulo & 58 & 8.2 \\
\hline Sergipe & 1 & 0.1 \\
\hline
\end{tabular}

physicians are more dissatisfied with the interference of sleeping problems in their activities of daily life than other healthcare professionals. In contrast, non-medical professionals reported greater dissatisfaction with the perception of others about the interference of sleep with their quality of life and were more stressed with their sleeping problems (Table 3).

When investigating habits and health aspects, $71.3 \%$ $(\mathrm{n}=506)$ said they did not need medication to adjust their sleep, but $28.7 \%(\mathrm{n}=204)$ reported using medication, and most of them were self-medicating $(n=123 ; 60.3 \%)$ (Table 4). Among the most used drugs were antidepressants $(n=54$; $7.6 \%$ ), benzodiazepines ( $\mathrm{n}=44 ; 6.2 \%)$, herbal medicines $(\mathrm{n}=37$; $5.2 \%)$, non-benzodiazepine hypnotic $(\mathrm{n}=28 ; 3.9 \%)$ and melatonin $(\mathrm{n}=20 ; 2.8 \%)$.

Most of the participants stated that they had observed a change in diet $(n=557 ; 78.5 \%)$ (Table 4$)$, especially related to the increase in carbohydrate intake alone $(\mathrm{n}=174 ; 24.5 \%)$, binge eating alone $(\mathrm{n}=72 ; 10.1 \%)$, and increased nighttime food intake alone ( $\mathrm{n}=37 ; 5.2 \%)$. In addition, many reported, at the same time, an intensification of carbohydrate intake, increasing nighttime food intake and binge eating $(n=125$; $17.6 \%$ ). Most respondents stated that they do not wake up in the middle of the night to eat $(\mathrm{n}=658 ; 92.7 \%)$. Food compulsion, in this study, was not defined as a nosological diagnosis, but as a subjective urgency to eat food in large quantities, followed by a feeling of well-being or relief at first and then by a feeling of guilt.

It was also observed that $27 \%(\mathrm{n}=192)$ of the individuals reported an increase in the consumption of alcoholic beverages, especially wine $(n=121 ; 14.2)$ and beer $(n=80 ; 11.2 \%)$. Of the total, $561(81.8 \%)$ reported a change in the practice of physical activity, with the majority having stopped exercising $(\mathrm{n}=383 ; 53.9 \%)$ or reduced the frequency of training $(\mathrm{n}=183$; $25.8 \%)$. Only $9.7 \%(n=69)$ of the professionals reported an increase in the frequency of performing physical exercises (Table 4).

\section{DISCUSSION}

The period of data collection for the study, which was from May to July 2020, coincided with the contagion plateau and the number of deaths in Brazil ${ }^{10}$.

A survey conducted in the Brazilian state of São Paulo in 2013, a pre-pandemic period, based on a sample of 1101 adults between 20 and 80 years old, found a prevalence of objective insomnia detected by polysomnography of $32 \%$, a subjective prevalence of insomnia symptoms of $45 \%$, and a subjective prevalence of insomnia detected by Diagnostic and Statistical Manual of Mental Disorders IV (DSM-IV) criteria of $15 \%$. In that study, although women corresponded to $47.3 \%$ of the general sample, they also made up $71.4 \%$ of individuals with insomnia according to the DSM-IV criteria. That 
Table 2. Data from Insomnia Severity Index self-reported by healthcare professionals during the SARS-CoV-2 pandemic.

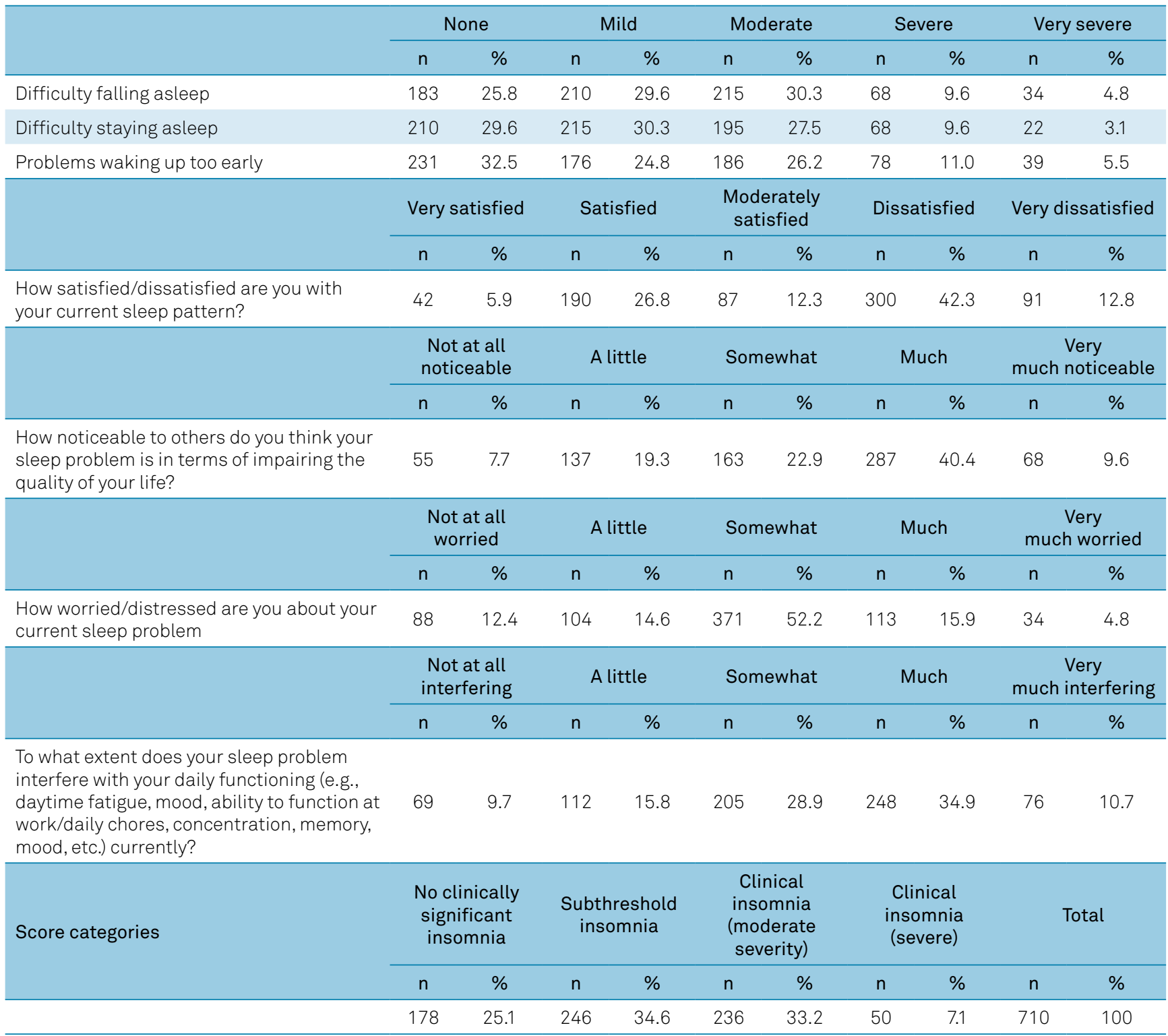

study also found the use of sleep-inducing medication in $5 \%$ of subjects with insomnia symptoms, compared to $2 \%$ of non-insomnia subjects and $12 \%$ of individuals with DSM-IV insomnia. Despite using the ISI-7 scale in its methods, an instrument also used in our work, the cited study did not provide, for comparison of results, the classification of the severity of insomnia or whether the insomnia presented difficulty falling asleep, difficulty staying asleep or problems waking up too early ${ }^{11}$.To our knowledge, there are no surveys about the sleep, eating and physical activity habits, all together, in a reasonable number of healthcare professionals.

An American survey carried out among obese people during social isolation due to the COVID-19 pandemic showed that $47.9 \%$ of these people reduced the frequency of physical activity and $55.9 \%$ its intensity ${ }^{12}$. Another study collected in Western Asia, North Africa and Europe revealed a
$38 \%$ reduction in physical activity among people in confinement $^{13}$. In the current study, $53.9 \%$ stopped practicing any exercise, while $25.8 \%$ reduced frequency or intensity, demonstrating that $79.7 \%$ of the healthcare professionals interviewed in Brazil experienced a negative impact regarding the performance of physical activity, a higher level than that for a confined population in other countries during the COVID-19 pandemic up to July $2020^{12,13,14}$.

Ruíz-Roso et al. ${ }^{15}$ reported that physical inactivity in Brazil among adolescents increased from 40.9 to $93 \%$ during the COVID-19 pandemic, a finding that is superior to that recorded in Chile, Colombia, Spain and Italy, by the same study.

In addition to being exposed to COVID-19 infection, the sedentary behavior displayed by most Brazilian professionals increases the propensity for morbidity and mortality related 
Table 3. Comparison between the self-reporting of the Insomnia Severity Index between physicians and other healthcare professionals.

\begin{tabular}{|c|c|c|c|c|c|c|c|c|c|c|c|c|}
\hline \multirow{2}{*}{ Variable } & \multicolumn{6}{|c|}{ Physicians ( $n=297)$} & \multicolumn{5}{|c|}{ Other healthcare professionals $(n=413)$} & \multirow{2}{*}{$p$-value* } \\
\hline & & $\mathrm{N}$ & Mi & Mo & $\mathrm{S}$ & VS & $\mathrm{N}$ & Mi & Mo & $\mathrm{S}$ & VS & \\
\hline \multirow{2}{*}{ Difficulty falling asleep } & $n$ & 94 & 99 & 73 & 22 & 9 & 89 & 111 & 142 & 46 & 25 & \multirow{2}{*}{$0.0001 * \star$} \\
\hline & $\%$ & $31.6 \%$ & $33.3 \%$ & $24.6 \%$ & $7.4 \%$ & $3.0 \%$ & $21.5 \%$ & $26.9 \%$ & $34.4 \%$ & $11.1 \%$ & $6.1 \%$ & \\
\hline \multirow{2}{*}{ Difficulty staying asleep } & $n$ & 105 & 100 & 66 & 20 & 6 & 105 & 115 & 129 & 48 & 16 & \multirow{2}{*}{$0.001 * *$} \\
\hline & $\%$ & $35.4 \%$ & $33.7 \%$ & $22.2 \%$ & $6.7 \%$ & $2.0 \%$ & $25.4 \%$ & $27.8 \%$ & $31.2 \%$ & $11.6 \%$ & $3.9 \%$ & \\
\hline \multirow{2}{*}{$\begin{array}{l}\text { Problems waking up too } \\
\text { early }\end{array}$} & $n$ & 106 & 73 & 74 & 28 & 16 & 125 & 103 & 112 & 50 & 23 & \multirow{2}{*}{0.553} \\
\hline & $\%$ & $35.7 \%$ & $24.6 \%$ & $24.9 \%$ & $9.4 \%$ & $5.4 \%$ & $30.3 \%$ & $24.9 \%$ & $27.1 \%$ & $12.1 \%$ & $5.6 \%$ & \\
\hline
\end{tabular}

N: none; Mi: mild; Mo: moderate; S: severe; VS: very severe.

\begin{tabular}{lccccccccccccccc}
\hline & & VS & S & MS & D & VD & VS & S & MS & D & VD & P-value \\
\hline $\begin{array}{l}\text { How satisfied/ } \\
\text { dissatisfied are you }\end{array}$ & $\mathrm{n}$ & 21 & 87 & 30 & 125 & 34 & 21 & 103 & 57 & 175 & 57 & \\
$\begin{array}{l}\text { with your current sleep } \\
\text { pattern? }\end{array}$ & $\%$ & $7.1 \%$ & $29.3 \%$ & $10.1 \%$ & $42.1 \%$ & $11.4 \%$ & $5.1 \%$ & $24.9 \%$ & $13.8 \%$ & $42.4 \%$ & $13.8 \%$ & 0.282 \\
\end{tabular}

VS: very satisfied; S: satisfied; MS: moderately satisfied; D: dissatisfied; VD: very dissatisfied.

\begin{tabular}{|c|c|c|c|c|c|c|c|c|c|c|c|c|}
\hline & & $N$ & $\mathrm{~L}$ & S & $M$ & V & $N$ & $\mathrm{~L}$ & S & $M$ & V & $\mathrm{p}$-value \\
\hline $\begin{array}{l}\text { How noticeable to } \\
\text { others do you think }\end{array}$ & $\mathrm{n}$ & 52 & 127 & 21 & 30 & 63 & 100 & 160 & 47 & 25 & 74 & \\
\hline $\begin{array}{l}\text { your sleep problem is in } \\
\text { terms of impairing the } \\
\text { quality of your life? }\end{array}$ & $\%$ & $17.5 \%$ & $42.8 \%$ & $7.1 \%$ & $10.1 \%$ & $21.2 \%$ & $24.2 \%$ & $38.7 \%$ & $11.4 \%$ & $6.1 \%$ & $17.9 \%$ & $0.029 * *$ \\
\hline \multirow{2}{*}{$\begin{array}{l}\text { How worried/distressed } \\
\text { are you about your } \\
\text { current sleep problem }\end{array}$} & $n$ & 144 & 47 & 9 & 53 & 37 & 212 & 66 & 25 & 35 & 67 & \multirow{2}{*}{$0.003 * *$} \\
\hline & $\%$ & $48.5 \%$ & $15.8 \%$ & $3.0 \%$ & $17.8 \%$ & $12.5 \%$ & $51.3 \%$ & $16.0 \%$ & $6.1 \%$ & $8.5 \%$ & $16.2 \%$ & \\
\hline
\end{tabular}

N: not at all worried; L: a little; S: somewhat; M: much; V: very much worried.

\begin{tabular}{|c|c|c|c|c|c|c|c|c|c|c|c|c|}
\hline & & $\mathrm{N}$ & $\mathrm{L}$ & S & $M$ & V & $\mathrm{N}$ & $\mathrm{L}$ & $S$ & $M$ & V & $p$-value \\
\hline To what extent does & $n$ & 86 & 102 & 21 & 40 & 39 & 104 & 146 & 55 & 29 & 73 & \\
\hline
\end{tabular}

your sleep problem

interfere with your

daily functioning (e.g.,

daytime fatigue, mood,

ability to function at

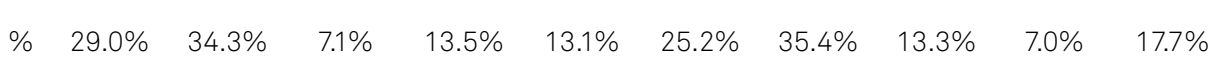

$0.002 * \star$

work/daily chores,

concentration, memory,

mood, etc.) currently?

N: not at all interfering; L: a little; S: somewhat; M: much; V: very much interfering.

\begin{tabular}{|c|c|c|c|c|c|c|c|c|c|c|}
\hline & & $\mathrm{NI}$ & Sul & $\mathrm{MI}$ & Sel & $\mathrm{NI}$ & Sul & $\mathrm{MI}$ & Sel & $\mathrm{p}$-value \\
\hline \multirow{2}{*}{ Score categories } & $\mathrm{n}$ & 86 & 109 & 86 & 16 & 92 & 137 & 150 & 34 & \multirow{2}{*}{$0.032 *$} \\
\hline & $\%$ & $29 \%$ & $36.7 \%$ & $29 \%$ & $5.3 \%$ & $22.3 \%$ & $33.2 \%$ & $36.3 \%$ & $8.2 \%$ & \\
\hline
\end{tabular}

NI: no clinically significant insomnia; Sul: subthreshold insomnia; MI: moderate insomnia; Sel: severe insomnia.

*Pearson's chi-square test; statistical significance $p<0.05$; **: statistical significance $p<0.05$.

to cardiovascular diseases, cancer and an increased incidence of type 2 diabetes mellitus ${ }^{16}$. The fight against physical inactivity through telecommunications, educational materials and government actions has been proposed by scientific entities such as the American Heart Association, the American College of Sports Medicine and the World Health Organization, due to the negative impact on physical inactivity related to the cardiovascular system ${ }^{17}$.

Approximately $70 \%$ of the healthcare professionals evaluated in our survey had some complaints related to insomnia, such as difficulty falling asleep, staying asleep or problems to waking up too early. High prevalence rates related to insomnia in the pandemic have also been found in Chinese studies. In the study by $\mathrm{Wu}^{18}$, all 60 physicians surveyed, who were COVID-19 frontliners, in their control group, had insomnia with some severity, considering that $61.67 \%$ of them corresponded to the score of moderate insomnia. Li, in another study ${ }^{19}$, showed that $58.9 \%$ of physicians surveyed in the city of Wuhan and $24.97 \%$ in the city of Ningbo showed insomnia with some severity. Lower 
Table 4. Data related to habits and general health aspects of healthcare professionals during the SARS-CoV-2 pandemic.

\begin{tabular}{lcc}
\hline & $\mathrm{n}$ & $\%$ \\
\hline Insomnia medication & 506 & 71.3 \\
No & 204 & 28.7 \\
Yes & & \\
Medication prescription & 204 & 100 \\
Total & 123 & 60.3 \\
I'm doing self-medication & 81 & 39.7 \\
There was a medical prescription & \\
Change in diet & 153 & 21.5 \\
No & 557 & 78.5 \\
Yes & & \\
Wake up in the middle of the night to eat & & 92.7 \\
No & 658 & 7.3 \\
Yes & 52 & \\
Increased consumption of alcoholic beverages & \\
No & 518 & 73.0 \\
Yes & 192 & 27.0 \\
Change in physical activity & & \\
No & 129 & \\
Yes & 581 & \\
\hline
\end{tabular}

prevalence of insomnia was reported by Lai et $\mathrm{al}^{6}$, whose study reports that $34 \%$ of physicians and nurses in their sample had insomnia to some degree, by Zhang ${ }^{20}$, whose study showed a prevalence of insomnia of $36.1 \%$ amongst physicians and nurses in Wuhan, and by Wang ${ }^{21}$, whose study found a prevalence of $38 \%$ of insomnia amongst physicians and nurses in a pediatric hospital in Wuhan. During the 2002 SARS epidemic, similar prevalence of insomnia among healthcare professionals was observed in Hong Kong $^{22}(34.2 \%)$ and Taiwan ${ }^{23}$ (37\%). Regarding the general population, sleep disorders in the current pandemic were reported by $37.6 \%$ of a Greek population sample, with a higher risk for women and residents of urban areas ${ }^{24}$.

Zhang et $\mathrm{a}^{20}$ describe the higher prevalence and severity of insomnia in nurses when compared to physicians. In this study, physicians and nurses were, for the most part, dissatisfied with their sleep, and insomnia among physicians was mostly mild, while among nurses, it was moderate, with some difficulty in falling asleep and maintaining sleep. Although physicians have shown greater interference of sleeping problems in their daytime activities, nurses reported greater stress related to these problems. Other studies of previous epidemics found higher levels of stress in nurses than in physicians and a greater probability of increasing the workload in nurses than in physicians ${ }^{25,26}$. There may be greater chances for physicians to work during the day, so they can sleep well at night, than nurses, whose hospital night shifts may be more frequent ${ }^{27}$. Another study demonstrated that more contact with patients with a more serious disease resulted in IES scores ${ }^{28}$. Physicians generally have less contact with patients than nurses. Nevertheless, it is common in the nursing profession to have more females than males. According to a meta-analysis ${ }^{29}$, women are more susceptible to insomnia, and studies on the current pandemic corroborate this statement ${ }^{19,20}$. Interestingly, in our study and in most studies found between insomnia and the pandemic of COVID-19 ${ }^{18,19,20}$, the samples consisted of substantially more women than men, which may have skewed the results.

In our sample, almost $30 \%$ of healthcare professionals started using some medication to adjust their sleep during pandemic and more than 50\% of these did it through selfmedication. A worrying result was the proportion of professionals self-medicating with drugs that would require medical prescriptions to be purchased and are, therefore, being used without any professional monitoring.

Regarding eating habits, the negative impact on Brazilian healthcare professionals seems to be greater than that found in other countries. Almandoz et al. ${ }^{12}$ describe that $12.1 \%$ of obese people did not eat any of the daily routine meals during the pandemic, a percentage which is at least $50 \%$ lower compared to Brazilian healthcare professionals of our survey. In this study, about half of the Americans interviewed stored food and $61.2 \%$ reported stress eating. In Italy, despite almost $50 \%$ of respondents reporting increased weight, there was greater adherence to the Mediterranean $\operatorname{diet}^{14}$, differently from our study, which showed a $60.8 \%$ increase in carbohydrate intake and binge eating in $30.3 \%$ of the sample.

The increase in the intake of ultra-processed foods during the lockdown was detected in adolescents living in both Latin America and the European continent ${ }^{15}$. China, on the other hand, showed an increase in the ingestion of vegetables, water, tea, coffee, fruits and grains, as well as a reduction in the consumption of sweet drinks and snacks ${ }^{4}$, due to the impact of campaigns related to food security and nutrition. While Ammar et al. reported a drastic reduction in alcohol consumption among their interviewers ${ }^{13}$, there was an increase in alcohol intake in $27 \%$ of Brazilian healthcare professionals in our survey.

The interference of the COVID-19 pandemic with quality of life appears to differ in each country ${ }^{12,13,14}$. In Brazil, according to our research, the healthcare professionals studied stopped or reduced the practice of physical activity and increased carbohydrate intake, which increases the propensity for weight gain ${ }^{30}$ and immune compromise ${ }^{31,32}$. About $40 \%$ showed dissatisfaction with the quality of sleep, and among those who started taking medication for sleep adjustment, most of them did it without medical advice.

Healthcare professionals are more susceptible to COVID-19 infection worldwide ${ }^{33}$. On August 14, 2020, the lethality rate in the general population of COVID-19 in the world was 3.64 according to WHO data ${ }^{2}$ and, in Brazil, 3.3\% 
according to the Ministry of Health ${ }^{3}$. Diet, sleep and physical activity, aspects of healthcare professionals evaluated in this study, are involved in the maintenance of body homeostasis and can certainly $y^{34,35,36,37}$ act, depending on the adjustment, as a risk or a protective factor for morbidity and mortality and possibly for mortality directly related to the COVID-19 infection.

The analysis of the data did not show significant differences between the results found in the sample from the state of Paraíba with the sample from the other Brazilian states. Despite this similarity of results, the low proportion in the sample coming from the other Brazilian states $-33.1 \%$ of the total population studied - when compared to the proportion of the sample coming from the state of Paraíba $66.9 \%$ of the total population studied - indicates a limitation of this study. Additional studies with more individuals from other states than Paraíba are necessary to verify the results found in our study for all of Brazil.

The main limitation of this study was the fact that the questionnaires are self-managed, which can bias the correct data. However, this was the possible research instrument during the period of need for social isolation so that biosafety could be respected. This is a strategy used by much of the current research on COVID-19 that we have consulted in our literature review. In addition, although this research is a cross-sectional study, the lack of a proper pre-pandemic control group is a limitation, and this would contribute to gauging a possible causality between the pandemic and the changes in sleep and habits found in the result. Further limitations are the overrepresentation of females and the relatively low number of participants in some regions.

In this study, Brazilian healthcare professionals displayed aspects of quality of life (physical activity, diet, alcohol intake and sleep) that were more affected during the COVID-19 pandemic compared to the findings of surveys of international studies for the general population. These are worrisome findings that indicate a need for greater assistance intervention for this group of professionals, who are so important to the population, especially in this period of coping with the pandemic.

\section{References}

1. Li Q, Guan X, Wu P, Wang X, Zhou L, Tong Y, et al. Early transmission dynamics in Wuhan, China, of novel coronavirus-infected pneumonia. N Engl J Med. 2020 Mar;382(13):1199-207. https://doi.org/10.1056/ NEJMoa2001316

2. World Health Organization. Coronavirus Disease (COVID-19). Situation Reports [accessed on 2020 Aug 23]. Available at: https:// www.who.int/emergencies/diseases/novel-coronavirus-2019/ situation-reports

3. Brazil. Ministério da Saúde. Coronavírus Brasil [accessed on 2020 Aug 23]. Available at: https://covid.saude.gov.br/

4. Luo M, Guo L, Yu M, Jiang W, Wang H. The psychological and mental impact of coronavirus disease 2019 (COVID-19) on medical staff and general public - a systematic review and meta-analysis. Psychiatry Res. 2020 Jun;291:113190. https://doi.org/10.1016/j. psychres.2020.113190

5. Holmes EA, O'Connor RC, Perry VH, Tracey I, Wessely S, Arseneault L, et al. Multidisciplinary research priorities for the COVID-19 pandemic: a call for action for mental health science. Lancet Psychiatry. 2020 Jun;7(6):547-60. https://doi.org/10.1016/S2215-0366(20)30168-1

6. Lai J, Ma S, Wang Y, Cai Z, Hu J, Wei N, et al. Factors Associated With Mental Health Outcomes Among Health Care Workers Exposed to Coronavirus Disease 2019. JAMA Netw Open. 2020 Mar;3(3):e203976. https://doi.org/10.1001/jamanetworkopen.2020.3976

7. Brazil. Ministério da Economia. Rede Ebserh. Empresa Brasileira de Serviços Hospitalares. [accessed on 2020 Aug 23]. Available at: https://www.gov.br/ebserh/pt-br/acesso-a-informacao/hospitaisuniversitarios-federais/rede-ebserh

8. Castro LS. Adaptação e validação do Índice de Gravidade de Insânia (IGI): Caracterização Populacional, Valores Normativos e Aspectos Associados. Adaptation and validation of the Insomnia Severity Index (ISI): population characteristics, normative values and associated factors. 2011 [accessed on 2020 Aug 23]. Available at: https:// repositorio.unifesp.br/handle/11600/23193

9. Thorndike FP, Ritterband LM, Saylor DK, Magee JC, Gonder-Frederick LA, Morin CM. Validation of the insomnia severity index as a webbased measure. Behav Sleep Med. 2011 Oct;9(4):216-23. https://doi. org/10.1080/15402002.2011.606766
10. Brazil. Ministério da Saúde. Boletim Epidemiológico no 25. Semana Epidemiológica 31 (26/07 a 01/08) [accessed on 2020 Aug 23]. Available at: https://coronavirus.saude.gov.br/boletinsepidemiologicos

11. Castro LS, Poyares D, Leger D, Bittencourt L, Tufik S. Objective prevalence of insomnia in the São Paulo, Brazil epidemiologic sleep study. Ann Neurol. 2013 Oct;74(4):537-46. https://doi.org/10.1002/ana.23945

12. Almandoz JP, Xie L, Schellinger JN, Mathew MS, Gazda C, Ofori A, et al. Impact of COVID-19 stay-at-home orders on weight-related behaviours among patients with obesity. Clin Obes. 2020 Jun;e12386. https://doi.org/10.1111/cob.12386

13. Ammar A, Brach M, Trabelsi K, Chtourou H, Boukhris O, Masmoudi $L$, et al. Effects of COVID-19 home confinement on eating behaviour and physical activity: results of the ECLB-COVID19 International Online Survey. Nutrients. 2020 Oct;12(6). https://doi. org/10.1101/2020.05.04.20072447

14. Di Renzo L, Gualtieri P, Pivari F, Soldati L, Attinà A, Cinelli G, et al. Eating habits and lifestyle changes during COVID-19 lockdown: an Italian survey. J Transl Med. 2020 Aug;18(1):229. https://doi. org/10.1186/s12967-020-02399-5

15. Ruíz-Roso MB, de Carvalho Padilha P, Matilla-Escalante DC, Brun P, Ulloa N, Acevedo-Correa D, et al. Changes of physical activity and ultra-processed food consumption in adolescents from different countries during Covid-19 pandemic: an observational study. Nutrients. 2020 Jul;12(8). https://doi.org/10.3390/nu12082289

16. Patterson R, McNamara E, Tainio M, de Sá TH, Smith AD, Sharp SJ, et al. Sedentary behaviour and risk of all-cause, cardiovascular and cancer mortality, and incident type 2 diabetes: a systematic review and dose response meta-analysis. Eur J Epidemiol. 2018 Sep;33(9):811-29. https://doi.org/10.1007/s10654-018-0380-1

17. Peçanha T, Goessler KF, Roschel H, Gualano B. Social isolation during the COVID-19 pandemic can increase physical inactivity and the global burden of cardiovascular disease. Am J Physiol Heart Circ Physiol. 2020 Jan;318(6):H1441-6. https://doi.org/10.1152/ ajpheart.00268.2020 
18. Wu K, Wei X. Analysis of psychological and sleep status and exercise rehabilitation of front-line clinical staff in the fight against COVID-19 in China. Med Sci Monit Basic Res. 2020 May;26:e924085. https:// doi.org/10.12659/MSMBR.924085

19. Li X, Yu H, Bian G, Hu Z, Liu X, Zhou Q, et al. Prevalence, risk factors, and clinical correlates of insomnia in volunteer and at home medical staff during the COVID-19. Brain Behav Immun. 2020 Jul;87:140-1. https://doi.org/10.1016/j.bbi.2020.05.008

20. Zhang C, Yang L, Liu S, Ma S, Wang Y, Cai Z, et al. Survey of insomnia and related social psychological factors among medical staff involved in the 2019 novel coronavirus disease outbreak. Front Psychiatry. 2020 Apr;11:306. https://doi.org/10.3389/ fpsyt.2020.00306

21. Wang S, Xie L, Xu Y, Yu S, Yao B, Xiang D. Sleep disturbances among medical workers during the outbreak of COVID-2019. Occup Med (Lond). 2020 Jul;70(5):364-9. https://doi.org/10.1093/occmed/kqaa074

22. Chua SE, Cheung V, Cheung C, McAlonan GM, Wong JWS, Cheung EPT, et al. Psychological effects of the SARS outbreak in Hong Kong on high-risk health care workers. Can J Psychiatry. 2004 Jun;49(6):3913. https://doi.org/10.1177/070674370404900609

23. Su T-P, Lien T-C, Yang C-Y, Su YL, Wang J-H, Tsai S-L, et al. Prevalence of psychiatric morbidity and psychological adaptation of the nurses in a structured SARS caring unit during outbreak: a prospective and periodic assessment study in Taiwan. J Psychiatr Res. 2007 Feb;41(12):119-30. https://doi.org/10.1016/j.jpsychires.2005.12.006

24. Voitsidis P, Gliatas I, Bairachtari V, Papadopoulou K, Papageorgiou G, Parlapani E, et al. Insomnia during the COVID-19 pandemic in a Greek population. Psychiatry Research. 2020 Jul;289:113076. https://doi.org/10.1016/j.psychres.2020.113076

25. Koh D, Lim MK, Chia SE, Ko SM, Qian F, Ng V, et al. Risk perception and impact of Severe Acute Respiratory Syndrome (SARS) on work and personal lives of healthcare workers in Singapore: what can we learn? Med Care. 2005 Jul;43(7):676-82. https://doi.org/10.1097/01. mlr.0000167181.36730.cc

26. Wong TW, Yau JKY, Chan CLW, Kwong RSY, Ho SMY, Lau CC, et al. The psychological impact of severe acute respiratory syndrome outbreak on healthcare workers in emergency departments and how they cope. Eur J Emerg Med. 2005 Feb;12(1):13-8. https://doi. org/10.1097/00063110-200502000-00005

27. Jehan S, Zizi F, Pandi-Perumal SR, Myers AK, Auguste E, JeanLouis G, et al. Shift work and sleep: medical implications and management. Sleep Med Disord. 2017;1(2). https://doi.org/10.5005/ jp-journals-10069-0006

28. Maunder RG, Lancee WJ, Rourke S, Hunter JJ, Goldbloom D, Balderson K, et al. Factors associated with the psychological impact of severe acute respiratory syndrome on nurses and other hospital workers in Toronto. Psychosom Med. 2004 Dec;66(6):938-42. https:// doi.org/10.1097/01.psy.0000145673.84698.18

29. Zhang B, Wing Y-K. Sex differences in insomnia: a meta-analysis. Sleep. 2006 Jan;29(1):85-93. https://doi.org/10.1093/sleep/29.1.85

30. Reyes-Olavarría D, Latorre-Román PÁ, Guzmán-Guzmán IP, JerezMayorga D, Caamaño-Navarrete F, Delgado-Floody P. Positive and negative changes in food habits, physical activity patterns, and weight status during COVID-19 confinement: associated factors in the Chilean population. Int J Environ Res Public Health. 2020 Jul;17(15). https://doi.org/10.3390/ijerph17155431

31. Damiot A, Pinto AJ, Turner JE, Gualano B. Immunological Implications of Physical Inactivity among Older Adults during the COVID-19 Pandemic. Gerontology. 2020 Jun;1-8. https://doi. org/10.1159/000509216

32. Simpson RJ, Kunz H, Agha N, Graff R. Exercise and the regulation of immune functions. Prog Mol Biol Transl Sci. 2015;135:355-80. https://doi.org/10.1016/bs.pmbts.2015.08.001

33. Kursumovic E, Lennane S, Cook TM. Deaths in healthcare workers due to COVID-19: the need for robust data and analysis. Anaesthesia. 2020;75(8):989-92. https://doi.org/10.1111/anae.15116

34. Afshin A, Sur PJ, Fay KA, Cornaby L, Ferrara G, Salama JS, et al. Health effects of dietary risks in 195 countries, 1990-2017: a systematic analysis for the Global Burden of Disease Study 2017. Lancet. 2019 May;393(10184):1958-72. https://doi.org/10.1016/ S0140-6736(19)30041-8

35. Seidelmann SB, Claggett B, Cheng S, Henglin M, Shah A, Steffen LM, et al. Dietary carbohydrate intake and mortality: a prospective cohort study and meta-analysis. Lancet Public Health. 2018 Sep;3(9):e419-28. https://doi.org/10.1016/s2468-2667(18)30135-x

36. Hublin C, Partinen M, Koskenvuo M, Kaprio J. Heritability and Mortality Risk of Insomnia-Related Symptoms: A Genetic Epidemiologic Study in a Population-Based Twin Cohort. Sleep. 2011 Jul;34(7):957-64. https://doi.org/10.5665/sleep.1136

37. Mok A, Khaw K-T, Luben R, Wareham N, Brage S. Physical activity trajectories and mortality: population based cohort study. BMJ. 2019 Jun;365. https://doi.org/10.1136/bmj.12323 